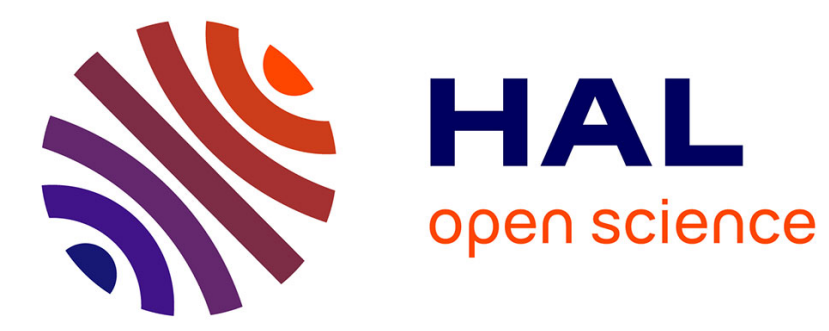

\title{
INFLUENCE OF PLASTIC DEFORMATION ON MAGNETOMECHANICAL DAMPING OF Co-Pt ALLOY
}

B. Augustyniak

\section{- To cite this version:}

B. Augustyniak. INFLUENCE OF PLASTIC DEFORMATION ON MAGNETOMECHANICAL DAMPING OF Co-Pt ALLOY. Journal de Physique Colloques, 1983, 44 (C9), pp.C9-455-C9-460. 10.1051/jphyscol:1983966 . jpa-00223416

\section{HAL Id: jpa-00223416 https://hal.science/jpa-00223416}

Submitted on 1 Jan 1983

HAL is a multi-disciplinary open access archive for the deposit and dissemination of scientific research documents, whether they are published or not. The documents may come from teaching and research institutions in France or abroad, or from public or private research centers.
L'archive ouverte pluridisciplinaire HAL, est destinée au dépôt et à la diffusion de documents scientifiques de niveau recherche, publiés ou non, émanant des établissements d'enseignement et de recherche français ou étrangers, des laboratoires publics ou privés. 
INFLUENCE OF PLASTIC DEFORMATION ON MAGNETOMECHANICAL DAMPING OF CO-PE ALLOY

\section{B. Augustyniak}

Institute of Physics, Techical University of Gdansk, 80-952 Gdansk, Poland

Résumé. La variation du frottement intérieur, en fonction de 1 'amplitude de la vibration, a été mesurêe sur en alliage de Co-Pt déformé plastiquement à des taux allant jusqu'à 1,2\%. L'amortissement magnétomécanique est discutê quantitativement en liaison avec le model de Smith et Bịrchak. La corrêlation entre la contrainte interne et la densitê de dislocation est estimée.

Abstract. Amplitude dependent internal friction of a disordered Co-Pt alloy was measured as function of a torsional plastic deformation up to $1.2 \%$. Magnetomechanical damping was quantitatively discussed using the Smith and Birchak model. The correlation between internal stress and dislocation density was estimated.

\section{INTRODUCTION}

Cobalt-platinum alloys near the equiatomic composition have a disordered face-centered cubic structure at high temperature but below $1098 \mathrm{~K}$ they undergo a phase transformation to form an ordered tetragonal structure with $c / a=0.88$ The degree of order strongly affects various properties of this alloy, among others its magnetic behaviour $[1,2,3]$ and also the internal friction. The internal friction in a disordered alloy is found to be much higher than in an ordered one [4] and strongly depends on vibration amplitude [5]. These effects are due to magnetomechanical hysteresis. In order to complete the investigation of this phenomenon we report the experimental data on the internal friction for samples in disordered state which were cold-worked. These results are compared with theory of Smith and Birchak [6].

\section{EXPERIMENTAL RESULTS}

The specimens were made in a form of wires of $1 \mathrm{~mm}$ in 


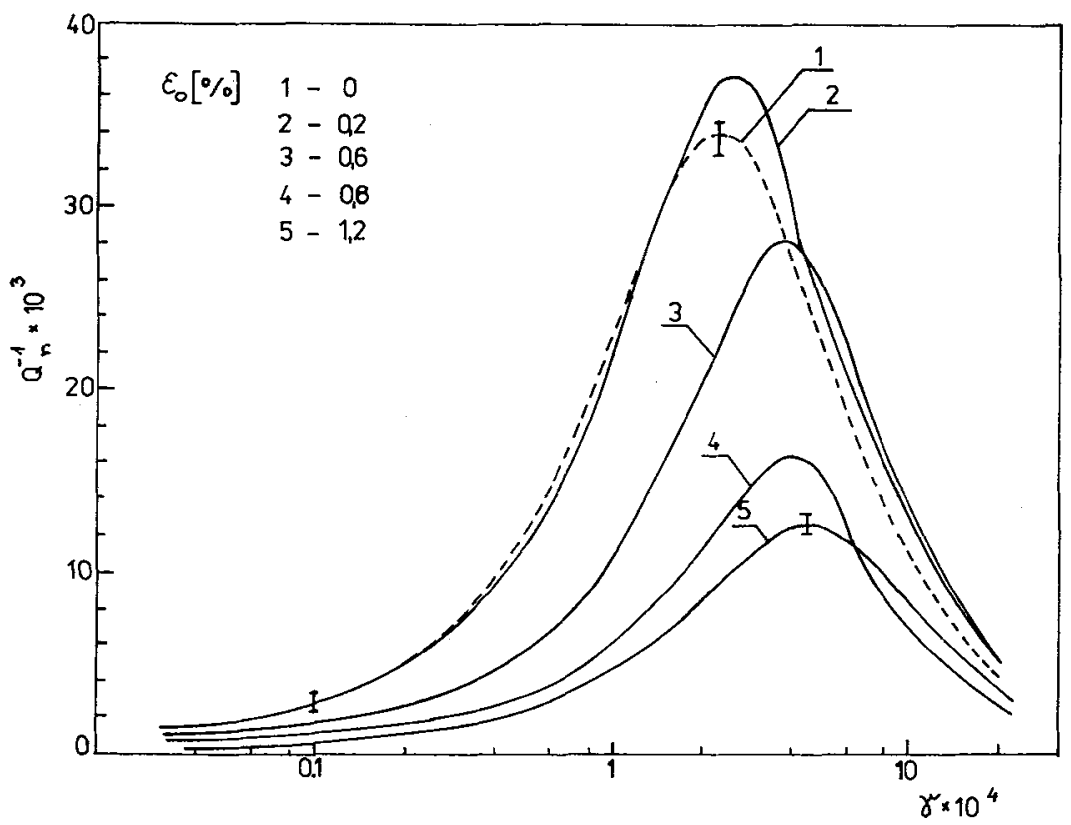

Fig.1. Amplitude dependence of magnetomechanical damping after plastic deformation

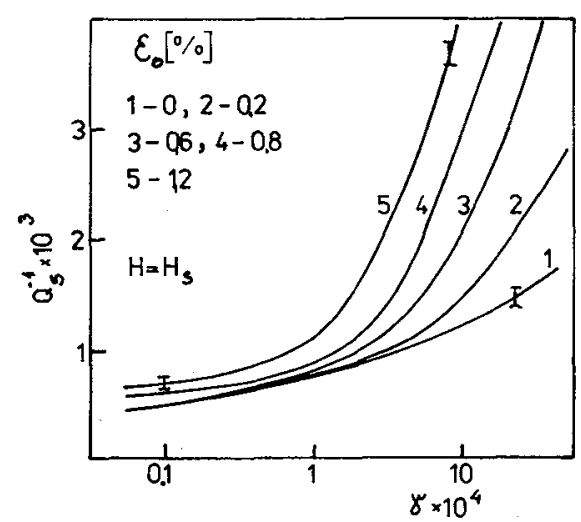

Fig.2. Amplitude dependent internal friction after plastic deformation

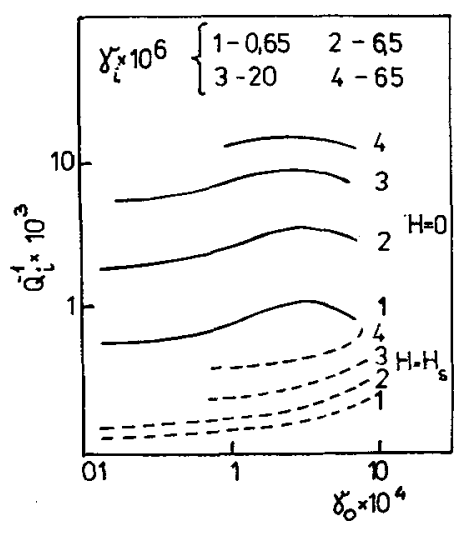

Fig.3. Low amplitude damping as function of the initial vibration amplitude $\gamma_{0}$ 


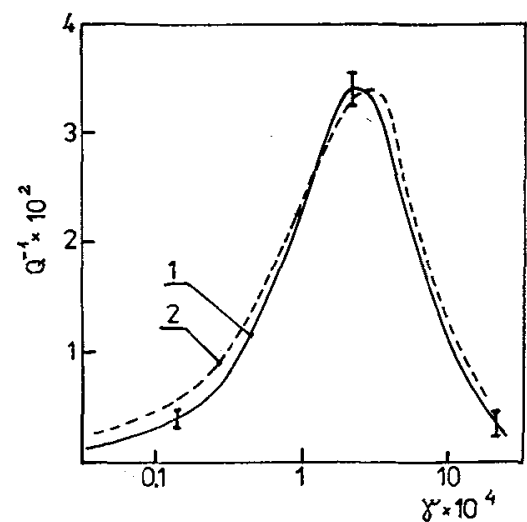

Fig.4. Magnet omechanical damping measured(1) and calculated ( 2 ).

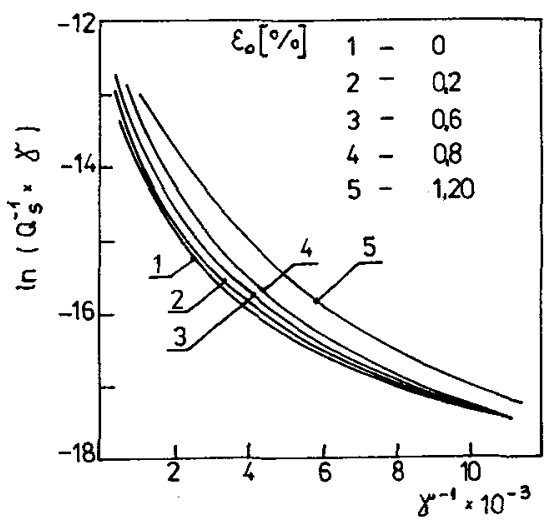

Fig.5. Granato-lücke plots as function of the plastic deformation.

diameter and a length of $50 \mathrm{~mm}$. According to the chemical analysis they contained 50.4 at of $\mathrm{Pt}$. The alloy in the dicordered state was obtained by quenching the sample from $1273 \mathrm{~K}$ into mineral oil at room temperature. The rate of quenching was estimated to be about $600 \mathrm{~K} / \mathrm{s}$.

The measurements of internal friction $\mathrm{Q}^{-1}$ were performed on an inverted torsion pendulum as a function of shear strain ranging from $1 \cdot 10^{-7}$ to $1 \cdot 10^{-3}$ and with or without saturating magnetic field $/ H=1.3 \cdot 10^{5} \mathrm{~A} / \mathrm{m} /$. The vibration frequency of the torsion pendulum was $40 \mathrm{~Hz}$.

Plastic deformation by torsion was performed in the pendulum for the four following values of $\varepsilon_{0}=0.2 ; 0.6 ; 0,8$; $1.2 / \% /$

Fig. 1 shows the results of the magnetic internal friction measurements for an undeformed sample /curve $1 /$ and for cold-worked one/curve 2 to 5/. The distinct internal friction maximum appears and it can be remarked that cold-work shifts this maximum to higher values of strain amplitudes. The plotted in Fig.1, values are after two corrections. At first the correction on uniform shear stress was made using standard formula $Q^{-1}=Q_{0}^{-1}+0.25 \gamma \cdot \partial Q_{0}^{-1} / \partial \gamma$. After that the amplitude dependent magnetic damping $Q^{-1}$ was estimated using the results, $\mathrm{Q}_{s}^{-1}$, of measurements in saturating magnetic field. The $\mathrm{Q}_{s}^{-1}$ values are plotted in Fig.2 as a function of the shear strain. The amplitude dependence measurements were performed starting 
from the highest value of vibration amplitude because the effect of prestrain appears [7] . Fig.3 shows two sets of damage curves. The two sets of $Q_{i}^{-1} / \gamma /$ dependences were measured without / solid line/ and with saturating field/dashed line/. These plots show that high oscillating amplitude increases low amplitude internal friction $Q_{s}^{-1}$. On the other hand, magnetic damping is decreased when $\gamma_{0}$ is higher than 2 to $5 \cdot 10^{-4}$. The subsequent recovery process is going for 5 to 10 hours.

\section{DISCUSSION}

Model of magnetomechanical damping, as proposed by Birchak and smith, gives a synonymous relationship between internal friction $\mathrm{O}^{-1}$ values and microscopic parameters such as internal stresses $\sigma_{i}$ and magnetostriction $\lambda_{s}$. Amplitude dependent magnetic damping is given by following formula [6]:

where $A=\frac{K \lambda_{s} E}{\sigma_{i}}$

$$
Q^{-1}(x)=A \frac{1-e^{-2 x} \cdot\left(1+2 x+2 x^{2}\right)}{x^{2}}
$$

with $x=\sigma / \sigma_{i}=\gamma / \gamma_{i} ; \quad \sigma_{i}$ is the average effective internal stress. Under torsional vibration, $\gamma$ is related to $\sigma$ by $\sigma=\sqrt{3} G \gamma$. $E$ and $G$ - are Young's and shear moduli, respectively; $K$ is $a$ shape coefficient for the magnetomechanical loop $/ K \leqslant 3 /$. From the maximum position of $Q^{-1} / x /$ function the $\sigma_{i}$ value can be calculated. The maximal value of damping is proportional to the A parameter.

The experimental results were described by function / $1 /$ using the least square procedure and $\sigma_{i}$ and $A$ parametors were estimated.

Fig.4 shows, for example, that calculated function/dashed curve/ fits well the experimental results/solid line, undeformed state/. The quantitative analysis gives that for initial state $\sigma_{i}=34 \pm 4 \mathrm{MPa}$. Knowing the magnetostriction value $\lambda_{5} \equiv \lambda_{111}=$ $32 \cdot 10^{-6}[8]$, the $K$ parameter was estimated: $K=1.5 \pm 0.5$, with agreement with the model. From our experiment results that the value of $\left|\lambda_{111} \cdot \sigma_{i}\right|$ product $/ 11 \cdot 10^{2} \mathrm{~J} / \mathrm{m}^{3} /$ is much lower than magnetocrystalline energy $/ K_{1}=-6.2510^{4} \mathrm{~J} / \mathrm{m}^{3}[\mathrm{~g}] /$. This relation points aut that external stresses which are near the $G_{i}$ value can not induce the rotation of magnetization vector inside the domain. So the amplitude dependence of $Q^{-1}$ results from the irreversible displacements of magnetic domain walls. 
The internal stress parameter $G_{i}$ is related to dislocation density [10]. Increase of dislocations density produces a decrease of maximum damping height and shifts it to higher shear strain. Our results, as shown in $\mathrm{Fig.1}$, are generally in agreement with this relationship.

From the magnetic damping measurements the $G_{i}$ values as function of plastic deformation ratio / $\varepsilon_{0} /$ can be determined. We want to find the correlation between this parameter and dislocation density $\rho$ which can be estimated from $Q_{s}^{-1} / \gamma /$ dependence. The amplitude dependent damping can be related to the models of Granato and Lücke [7]. Granato-Lücke plots are shown in Fig.5. Theory predicts a linear relationship, but the only data which can be adjudged to even approximate to linearity are those from the lower amplitudes. Fig. 5 shows that cold-work shifts only the G-L plots without changing the slope. It suggests that plastic deformation increases dislocation density and that dislocation length is unchanged. Thus the $Q_{s}^{-1}$ internal friction should be proportional to $\rho$, as measured at the same amplitude of vibra$t$ ion and for different $\varepsilon_{0}$ values.

The $\sigma_{i}$ parameter values which were determined from the magnetomechanical damping measurements are plotted as function of

$\varepsilon_{0}$ in Fig. 6 /Curve 1/. This curve indicates that internal

friction increases rapidly for $\varepsilon_{0}=0.2 \%$ and that $\sigma_{i}$ is proportional to $\varepsilon_{0}$ for higher plastic deformation. On the other hand we have calculated the values of $A$ parameter which is proportional to the damping maximum height /eq.1/. The $A / \varepsilon_{0} /$ function is represented by curve 2 in Fig.6. For $\varepsilon_{0}=0.2 \%$ this parameter is increased unexpectedly. For the higher values of $\varepsilon_{0}$ the magnetomechanical damping decreases monotonously as shown by curve 2 in Fig.6. For testing the validity of adopted model after cold-work, the $K / \varepsilon_{0} /$ dependence was examined. The product values were plotted vs $\varepsilon_{0}$ in Fig.6/curve $3 /$. The assumption was made that $E$ and $\lambda$ parameters did not change strongly after the cold-work. From the shape of curve 3 one can deduced that the $K$ parameter increases at first about twicely

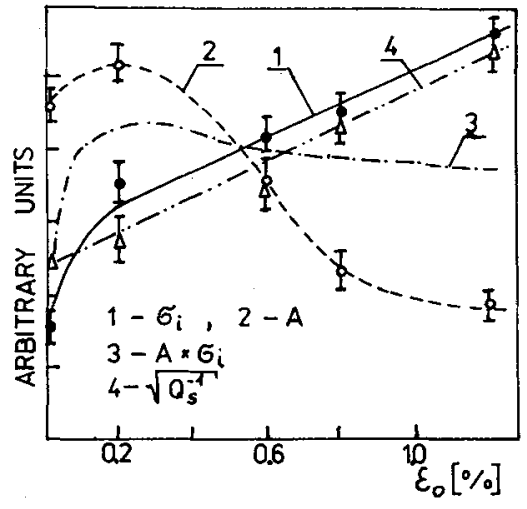

Fig.6. Cold-work dependence of : 1 - internal stress, 2 - magnetic damping. 3 - hysteresis loop parameter, 3 - dislocation density. and rests constant for higher values, being smaller than 3 . That confirms the Birchak and Smith model.

Finaliy, the last relationship between $\sigma_{i}$ and $\rho$ can be examined. The square root values of $Q_{s}^{-1}$ $/ \gamma=8 \cdot 10^{-5} /$ are plotted as curve 4 in Fig.6. The evident linear dependence appears. The comparison between two curves: 1 and 4 in Fig.6 leads to the conclusion that $G_{i}$ parameter is well correlated with the dislocation density and for higher value of $\sigma_{i}$, this relation is like $\sigma_{i} \sim \sqrt{\rho}$. The $\mathrm{Qs}_{\mathrm{s}}^{-1}$ is sensitive to the dislocations which are mobile in the field of periodic stress. Magnetorechanical damping $\mathrm{Oh}_{h}^{-1}$ is sensitive to the fixed dislocations which are able to anchor the Bloch walls [11]. We assume 
that small plastic deformation /II etap of hardening/ creates new dislocations [12]. It confirms the results shown in Fig.2. High strain, during $\underline{Q}^{-1}$ measurements, increases also the mobile dislocation density and thus raises the damping at lower strain $/ F i g .3 /$. The part of new dislocations can be pinned by small inclusions of ordered phase $/ d=100 \AA /$. It increases the local internal stresses near by these inclusions and decreases the magnetomechanical damping. The remarkable increase of $Q^{-1}$ which appears for $\varepsilon_{0}=0.2 \%$ can be explained as follows. Such deformation changes the domain structure of material. The magnetic domain wall are then unpinned from stable defects /vacancies as quenched and second phase precipitations/. Phenomenologically it increases the $K$ parameter value.

\section{CONCLUSIONS}

1. Magnetomechanical internal friction in disordered Co-Pt alloy can be described qualitatively by Birchak and Smith theory.

2. Magnetic damping is influenced by cold-work because of increasing density of dislocations.

\section{REFERENCES}

1 NEWKIRK J.B., GEISLER A.H., Trans.AIME, Journ.Met., 188, $1249 / 1950 /$.

2 EURIN P.. PAULEVE J.. IEEE Trans.Mag. $5,216 / 1963 /$.

3 SHCHEGOLEVA N.N., MAGAT L.M., SHUR Ya. S., Fiz.Met. Metalloved. 34, 633/1972/.

4 CHOMKA W.. BELSON J., EURIN P., PAULEVE J.. Comt .Rend. C 270. 2042/1970/.

5 CHOMKA W.., AUGUSTYNIAK B., Nuovo Cimento, 33 B. 375/1979/

6 SMITH G.W., BIRCHAK J.R., J.Appl.Phys. 40, 5174/1969/. 41. 3315/1970/.

7 DE BATIST R.. Internal Friction of Structure Defects in Crystalline solids, North Holland Publishing Co./1970/pp. 347-352.

8 POUCHY J., WAINTAL A., Solid Sta:e Com. 17, 1227/1975/.

9 MC CURRIE R.A., GAUNT P., Phil.Mag. 13, 567/1966/.

10 HONIKOMB R., Plastic Deformation of Metals, Moskow, Mir /1972/.

11 ACZEL O.F.G., ROTHENSTEIN B.F., Chech.J.Phys. B20, 953/1970/.

12 BERNSTEIN M.L., Structure of Deformed Metals, Moskow, Metalurgia /1977/. 